\title{
Janus kinase inhibitors in rheumatoid arthritis
}

\section{Clinical applications}

\section{Jennifer Walker \\ Associate professor \\ Malcolm Smith \\ Professor \\ Department of \\ Rheumatology \\ Repatriation General \\ Hospital \\ Adelaide}

\section{Key words}

molecular targeted therapy, tofacitinib

Aust Prescr 2014;37:158-60

\section{SUMMARY}

Tofacitinib, an oral Janus kinase inhibitor, is an effective treatment for rheumatoid arthritis.

Adverse effects are generally mild and include cytopenias and hyperlipidaemia.

Opportunistic infections such as herpes zoster may occur with tofacitinib.

\section{Introduction}

Despite the advent of biological therapies for rheumatoid arthritis, many patients continue to experience unacceptable levels of disease. Furthermore, biological drugs have to be administered parenterally.

Janus kinase inhibitors are oral drugs. They interfere with signalling through type I and II cytokine receptors which have been shown to be critical in rheumatoid arthritis.

\section{Tofacitinib}

Tofacitinib is an oral Janus kinase inhibitor with preferential inhibition of Janus kinase 3 and 1 over Janus kinase 2. It has an oral bioavailability of $74 \%$ and a mean elimination half-life of approximately three hours. Most (70\%) of the drug is metabolised (CYP3A4 predominant) and $30 \%$ is renally excreted. ${ }^{2}$

Tofacitinib $5 \mathrm{mg}$ twice a day has recently been approved by the US Food and Drug Administration for moderate to severe rheumatoid arthritis refractory to disease-modifying treatments. ${ }^{3}$

\section{Phase II trials}

In phase II studies, tofacitinib was superior to placebo when added to methotrexate in patients with rheumatoid arthritis. ${ }^{4,5}$ Responses were observed quickly, often within one week. Furthermore, small numbers of patients were able to switch from adalimumab to tofacitinib without difficulty. ${ }^{6}$ In the initial studies, tofacitinib was tolerable at doses of $5 \mathrm{mg}$ and $10 \mathrm{mg}$ twice daily.

\section{Phase III trials}

Several phase III trials have been conducted to assess the efficacy and safety of tofacitinib in patients with rheumatoid arthritis (see Table). The American College of Rheumatology 20 criteria (ACR 20) were used to measure response rates (see Box).

\section{ORAL Solo trial}

A six month, double-blind study enrolled 611 patients who had not had an adequate response to at least one non-biological or biological disease-modifying drug. Patients received placebo or tofacitinib $5 \mathrm{mg}$ or $10 \mathrm{mg}$ twice daily in addition to usual care. Antimalarial drugs, non-steroidal anti-inflammatory drugs and glucocorticoids ( $\leq 10 \mathrm{mg}$ prednisone/day) were permitted but all other disease-modifying drugs were discontinued for the trial.

A clinical benefit was demonstrated, but there was no significant increase in the number of patients entering remission according to disease activity score criteria. ${ }^{7}$ This suggested that while tofacitinib is effective as a monotherapy, additional disease-modifying therapy may be required.

\section{ORAL Standard trial}

Another study assessed tofacitinib as an add-on therapy in patients who had not responded adequately to methotrexate. This was a 12-month study of 717 patients on stable doses of methotrexate. They were given tofacitinib $5 \mathrm{mg}$ or $10 \mathrm{mg}$ twice daily, adalimumab $40 \mathrm{mg}$ every two weeks, or placebo. The study showed similar clinical benefit with the active treatments over placebo as well as an increase in numbers of patients entering remission at six months (based on a disease activity score). ${ }^{8}$

\section{ORAL Step study}

Responses among patients with more resistant disease have also been assessed. A six-month study enrolled 399 people who had not responded to at least one tumour necrosis factor inhibitor. Patients were randomised to placebo or tofacitinib (5 mg or $10 \mathrm{mg}$ twice a day). After three months, patients who received placebo were transferred to tofacitinib. Once again, significant improvements were observed in ACR 20 response rates after three months and 
on a disability questionnaire (Health Assessment Questionnaire-Disability Index). However, among these patients with more resistant disease, there was no significant increase in rates of remission. ${ }^{9}$

\section{ORAL Sync study}

The ORAL Sync study, reported as a conference abstract, assessed the addition of tofacitinib to treatment in patients who had ongoing disease despite receiving disease-modifying drugs. This trial design is likely to most closely reflect current clinical practice. Again, the study showed an improved response rate and disability score with tofacitinib, and a significant increase in the number of patients achieving remission. ${ }^{10}$

\section{Radiological outcomes}

More recently, 12-month data looking at radiological outcomes with tofacitinib and methotrexate suggest that tofacitinib inhibits structural progression, both as solo therapy (to a greater level than methotrexate) and with background methotrexate use. ${ }^{11,12}$

\section{Adverse events}

The most common adverse events with tofacitinib were diarrhoea, nasopharyngitis, urinary tract infection, nausea and headache. The risk of infection is an important consideration, although a recent meta-analysis concluded that it was similar to the risk with biological therapies.

There have been 12 cases of tuberculosis reported in the trial cohorts, 11 of whom initially screened negative for the disease. Ten cases occurred in countries endemic for tuberculosis.

The incidence of herpes zoster is also increased with tofacitinib. In a pooled analysis of phase II, III and long-term extension studies (4789 patients with 5651 patient-years of tofacitinib treatment), 239 patients experienced herpes zoster. One case was multidermatomal, none involved visceral dissemination and there were no fatalities. ${ }^{13}$

Pooled analyses favour a $5 \mathrm{mg}$ twice-daily dose of tofacitinib to reduce the risk of serious infection (seen in long-term extension studies). The transient effects of tofacitinib mean that its immunomodulatory effect can be rapidly reversed if sepsis occurs..$^{9,14,15}$

Hyperlipidaemia has been consistently observed in the trials and may relate to inhibition of interleukin- 6 signalling. ${ }^{14}$ Atorvastatin appears to reduce the increase in cholesterol, ${ }^{16}$ but long-term cardiovascular effects will need to be assessed in the future.

Elevations in liver aminotransferases, neutropenia, thrombocytopenia and anaemia have all been reported. Changes are generally mild. A small rise in serum creatinine has been noted, but at this stage

\section{Table Phase III trials of tofacitinilb in rheumatoid arthritis}

\begin{tabular}{lll}
\hline Trials & Treatment given twice daily & Response rate ACR 20 \\
\hline ORAL Solo trial & tofacitinib $5 \mathrm{mg}$ & $59.8 \%$ \\
(3 month end point) $^{7}$ & tofacitinib $10 \mathrm{mg}$ & $65.7 \%$ \\
& placebo & $26.7 \%$ \\
ORAL Standard trial & tofacitinib $5 \mathrm{mg}$ & $51.5 \%$ \\
(6 month end point) $^{8}$ & tofacitinib 10 mg & $52.6 \%$ \\
& placebo & $28.3 \%$ \\
ORAL Step study & tofacitinib 5 mg & $41.7 \%$ \\
(3 month end point) $^{9}$ & tofacitinib $10 \mathrm{mg}$ & $48.1 \%$ \\
& placebo & $24.4 \%$ \\
ORAL Sync study & tofacitinib 5 mg & $52.7 \%$ \\
(6 month end point) & tofacitinib $10 \mathrm{mg}$ & $58.3 \%$ \\
& placebo & $31.2 \%$
\end{tabular}

ACR 20 American College of Rheumatology response criteria (see Box)

Box Measuring response to treatment in rheumatoid arthritis

The American College of Rheumatology (ACR) response criteria are a standard instrument used in rheumatoid arthritis trials.

The ACR criteria of $20 \%, 50 \%$ or $70 \%$ improvement in clinical manifestations are an attempt to quantify response to therapy. Thus, a patient with an ACR 20 response to an intervention has demonstrated a $20 \%$ decrease in the combined number of swollen and tender joint counts, and a $20 \%$ improvement in any 3 of the 5 core-set measures which include Patient's Global Assessment, Physician's Global Assessment of disease activity (on $10 \mathrm{~cm}$ visual analogue scale), Patient's Assessment of Pain score (on $10 \mathrm{~cm}$ visual analogue scale), Health Assessment Questionnaire Disability Index (HAQ-DI), and acute phase reactants (erythrocyte sedimentation rate or C-reactive protein).

The achievement of an ACR 20 response by an individual is considered to be the minimally achieved level of response that is of clinical relevance.

See: www.rheumatology.org

has not been clinically significant. ${ }^{14,15}$ As yet, there has been no reported increase in malignancy, but longterm data are still needed.

\section{Other indications}

Tofacitinib has shown promising results in phase II trials in other autoimmune diseases including ulcerative colitis and psoriasis. It is also being assessed as an immunosuppressant in renal transplant recipients. ${ }^{17-19}$ 


\section{Conclusion}

Tofacitinib is not yet available in Australia, but its release will provide an alternative option and effective oral treatment for patients with rheumatoid arthritis resistant to standard therapy. While initial data are promising, longer-term studies are required to better assess the risk of malignancy, opportunistic infection and radiological changes. Other Janus kinase inhibitors are currently undergoing clinical trials for rheumatoid arthritis. ${ }^{3}<$

Conflict of interest: none declared

\section{REFERENCES}

1. O'Shea JJ, Kontzias A, Yamaoka K, Tanaka Y, Laurence A. Janus kinase inhibitors in autoimmune diseases. Ann Rheum Dis 2013;72 Suppl 2:ii111-5.

2. Bannwarth B, Kostine M, Poursac N. A pharmacokinetic and clinical assessment of tofacitinib for the treatment of rheumatoid arthritis. Expert Opin Drug Metab Toxicol 2013:9:753-61.

3. van Vollenhoven RF. Small molecular compounds in development for rheumatoid arthritis. Curr Opin Rheumatol 2013;25:391-7.

4. Kremer JM, Cohen S, Wilkinson BE, Connell CA, French JL, Gomez-Reino J, et al. A phase Ilb dose-ranging study of the oral JAK inhibitor tofacitinib (CP-690,550) versus placebo in combination with background methotrexate in patients with active rheumatoid arthritis and an inadequate response to methotrexate alone. Arthritis Rheum 2012;64:970-81.

5. Tanaka Y, Suzuki M, Nakamura H, Toyoizumi S, Zwillich SH; Tofacitinib Study Investigators. Phase II study of tofacitinib (CP-690,550) combined with methotrexate in patients with rheumatoid arthritis and an inadequate response to methotrexate. Arthritis Care Res (Hoboken) 2011;63:1150-8.

6. Fleischmann R, Cutolo M, Genovese MC, Lee EB, Kanik KS, Sadis $S$, et al. Phase Ilb dose-ranging study of the oral JAK inhibitor tofacitinib (CP 690,550) or adalimumab monotherapy versus placebo in patients with active rheumatoid arthritis with an inadequate response to disease-modifying antirheumatic drugs. Arthritis Rheum 2012;64:617-29.

7. Fleischmann R, Kremer J, Cush J, Schulze-Koops H, Connell CA, Bradley JD, et al; ORAL Solo Investigators. Placebo-controlled trial of tofacitinib monotherapy in rheumatoid arthritis. N Engl J Med 2012;367:495-507.

8. van Vollenhoven RF, Fleischmann R, Cohen S, Lee EB, Garcia Meijide JA, Wagner S, et al; ORAL Standard Investigators. Tofacitinib or adalimumab versus placebo in rheumatoid arthritis. N Engl J Med 2012;367:508-19.

9. Burmester GR, Blanco R, Charles-Schoeman C, Wollenhaupt J, Zerbini C, Benda B, et al; ORAL Step Investigators. Tofacitinib (CP-690,550) in combination with methotrexate in patients with active rheumatoid arthritis with an inadequate response to tumour necrosis factor inhibitors: a randomized phase 3 trial. Lancet 2013;381:451-60.

10. Kremer J, Li ZG, Hall S, Fleischmann R, Genovese M, Martin-Mola E, et al. Tofacitinib (C-690,550) an oral Janus kinase inhibitor, in combination with traditional DMARDs: a phase 3 efficacy and safety study in patients with active rheumatoid arthritis with inadequate response to DMARDs [abstract]. Ann Rheum Dis 2011;70(Suppl 3):170.
11. van der Heijde D, Tanaka Y, Fleischmann R, Keystone E, Kremer J, Zerbini C, et al. Tofacitinib (C-690,550) in patients with rheumatoid arthritis receiving methotrexate: Twelvemonth data from a twenty-four-month phase III randomized radiographic study. Arthritis Rheum 2013;65:559-70.

12. Lee EB, Fleischmann RM, Hall S, van Vollenhoven RF, Bradley J, Gruben D, et al. Radiographic, clinical and functional comparison of tofacitinib monotherapy versus methotrexate in methotrexate-naïve patients with rheumatoid arthritis [abstract]. Arthritis Rheum 2012;64 Suppl 10:S2486.

13. Winthrop KL, Yamanaka H, Valdez H, Mortensen E, Chew R, Krishnaswami S, et al. Herpes zoster and tofacitinib therapy in patients with rheumatoid arthritis. Arthritis Rheum 2014 DOI: 10.1002/art.38745.

14. Salgado E, Maneiro JR, Carmona L, Gomez-Reino JJ. Safety profile of protein kinase inhibitors in rheumatoid arthritis: systematic review and meta-analysis. Ann Rheum Dis 2014;73:871-2.

15. Cohen S, Krishnaswami S, Benda B, Riese R, Boy MG Gruben D, et al. Tofacitinib, an oral Janus kinase inhibitor: analyses of efficacy and safety of 10 versus $5 \mathrm{mg}$ twice daily in a pooled phase 3 and long-term extension rheumatoid arthritis population [abstract]. Arthritis Rheum 2012;64 Suppl 10;2485.

16. Mclnnes IB, Kim HY, Lee SH, Mandel D, Song YW, Connell CA et al. Open-label tofacitinib and double-blind atorvastatin in rheumatoid arthritis patients: a randomized study. Ann Rheum Dis 2014;73:124-31.

17. Mehta SJ, Silver AR, Lindsay JO. Review article: strategies for the management of chronic unremitting ulcerative colitis. Aliment Pharmacol Ther 2013;38:77-97.

18. Mamolo C, Harness J, Tan H, Menter A. Tofacitinib (CP-690,550), an oral Janus kinase inhibitor, improves patient-reported outcomes in a phase $2 \mathrm{~b}$, randomized, double-blind, placebo-controlled study in patients with moderate-to-severe psoriasis. J Eur Acad Dermatol Venereol 2013. doi:10.1111/jdv.12081. Epub ahead of print.

19. Vincenti F, Tedesco SH, Busque S, O'Connell P, Friedewald J, Cibrik D, et al. Randomized phase $2 b$ trial of tofacitinib (CP-690,550) in de novo kidney transplant patients: efficacy, renal function and safety at 1 year. Am J Transplant 2012;12:2446-56.

\section{FURTHER READING}

Kubler P. Experimental and clinical pharmacology. Janus kinase inhibitors: mechanisms of action. Aust Prescr 2014;37:154-7.
Bazargan A, Tam C. Experimental and clinical pharmacology. Janus kinase inhibitors in myeloproliferative neoplasms: clinical applications. Aust Prescr 2014;37:161-2.

New drugs: Ruxolitinib. Aust Prescr 2013;36:212-8. 